\title{
Unorthodox ophthalmic preparations on the Ghanaian market: a potential risk for ocular and enteric infections
}

\author{
Samuel Kyei ${ }^{1,3}$, Eric Dogbadze ${ }^{2}$, Selassie Tagoh ${ }^{3}$, Estele Mwanza ${ }^{4}$
}

1. Department of Optometry and Vision Science, School of Allied Health Sciences, College of Health and Allied Sciences, University of Cape Coast, Cape Coast, Ghana.

2. Department of Biomedical Sciences, School of Allied Health Sciences, College of Health and Allied Sciences, University of Cape Coast, Cape Coast, Ghana.

3. Department of Optometry, Faculty of Science and Engineering, Bindura University of Science Education, Bindura, Zimbabwe.

4. Department of Health Sciences, Faculty of Science and Engineering, Bindura University of Science Education, P. Bag 1020, Bindura, Zimbabwe.

\begin{abstract}
Purpose: Microbial contamination of orthodox ophthalmic preparations poses a serious threat to the user by causing ocular infections. There is no such information about unorthodox ophthalmic preparations in a medical pluralistic system such as Ghana. The aim of this study was to assess unorthodox ophthalmic medications on the Ghanaian market for possible microbial contaminations.

Methods: Unorthodox ophthalmic preparations were collected across different herbal and homeopathic outlets in Ghana. A total of 27 samples were collected from the ten (10) regions in Ghana. The samples were inoculated in different culture media (Plate count Agar, Blood Agar, MacConkey Agar, Saboraud Dextrose Agar). The microorganisms isolated were identified using standard microbiological procedures and antimicrobial susceptibility was done to determine whether they were resistant or susceptible strains.

Results: All the samples were contaminated with bacteria and the majority were contaminated with fungus. A total of forty-eight bacteria spp. was isolated thus seven different types namely: Staphylococcus aureus, Bacilli spp., Serrati spp., Escherichia coli, Pseudomonas spp., Klebsiella spp. and Shigella spp. with Staphylococcus aureus being the predominant bacteria. For fungi, a total of eleven fungi species thus four different types namely: Cephalosporium spp., Penicillium spp., Cercosporium spp. and Clasdosporium spp. with the predominant fungi being Penicillium spp. Per the class of preparations, 15 contaminants were isolated from ten (10) anti-inflammatory preparations. The fungi were all susceptible to both Ketoconazole and Fluconazole but the bacteria were resistant to all the conventional antibiotics except Ciprofloxacin and Gentamycin.

Conclusion: Unorthodox ophthalmic preparations found on the Ghanaian market are contaminated with bacteria and fungi of clinical importance.
\end{abstract}

Keywords: Risk of infections, unorthodox medicine, ocular infection, corneal ulcers, fungal keratitis.

DOI: https://dx.doi.org/10.4314/ahs.v20i1.58

Cite as: Kyei S, Dogbadze E, Tagoh S, Mwanza E. Unorthodox ophthalmic preparations on the Ghanaian market: a potential risk for ocular and enteric infections. Afri Health Sci. 2020;20(1):515-23. https:// dx.doi.org/10.4314/ahs.v20i1.58

\section{Introduction}

Ghana is a medical pluralistic country which practices both unorthodox and orthodox medicine. The World

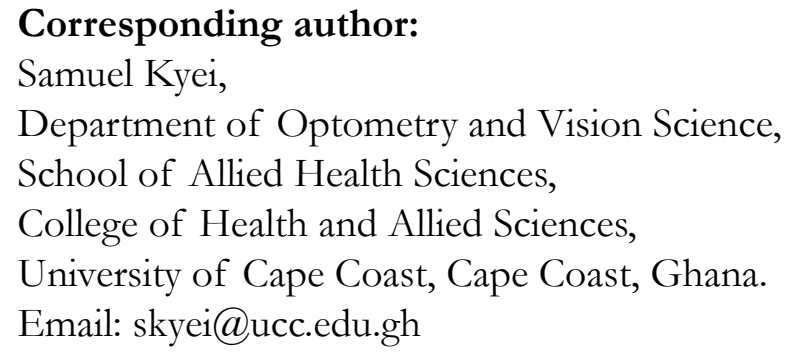

Health Organization estimates that 70 to $80 \%$ of people in the world depend on unorthodox medicine including herbal products as their primary therapeutic agents. Specifically, approximately $70 \%$ of Ghanaians depend exclusively on traditional medicine for their primary health care. ${ }^{1-4}$ The use of traditional herbal medicine has increased in Ghana due to the availability of raw materials, easy access and more importantly low cost of herbal medicine as compared to the synthetic drugs on the Ghanaian market. ${ }^{5}$ Although there has been an increase in the use of these unorthodox preparations, their qual-

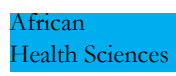

C) 2020 Kyei S et al. Licensee African Health Sciences. This is an Open Access article distributed under the terms of the Creative commons Attribution License (https:// creativecommons.org/licenses/BY/4.0), which permits unrestricted use, distribution, and reproduction in any medium, provided the original work is properly cited. 
ity and safety profiles have not been investigated. Most unorthodox preparations are used in different forms and may carry a great number of microbes originating from roots of herbs, stems and leaves. ${ }^{6}$ Herbal medications are likely to be contaminated with a wide variety of other potentially pathogenic microbes ${ }^{7}$ mainly due to the high probability of contaminations during collection of raw materials or processing owing to the poor quality controls or hygienic practices adhered to during manufacturing. Notwithstanding the fact that sterility is a key requirement for ophthalmic preparations, given the route of administration and the potential risks of serious infection and blindness for users, if sterility is compromised. ${ }^{8}$ Currently, studies from poor regions of the world have indicated a population incidence of infectious keratitis to be 113-799 per 100 000/year a rate that are 10-70 times higher than in Western countries. ${ }^{9}$ The situation is no better with diarrheal diseases stemming resulting from enteric infections.. ${ }^{10}$ This gives credence to the fact that all possible contributors to this threat be assessed to inform policy direction.

Apart from the risk of infections, bacterial and fungal contaminations reduce the efficiency and potency of such preparations as they degrade the active ingredients and alter the $\mathrm{pH}$ thus affecting their potency and efficacy. ${ }^{11}$

Unorthodox ophthalmic preparations (solid, semi-solid, liquid) are prepared from plant leaves, mineral substances, bark, seed, root or any of such combinations. ${ }^{8}$

Conventional and standard microbiological methods are currently used for routine testing for pharmaceutical bacterial contaminants, but with herbal ophthalmic products, microbial testing is mostly not done. Most multiple use orthodox ophthalmic preparations contain anti-microbial substances such as preservatives but the same cannot be said of unorthodox ophthalmic preparations. The widespread use of herbal products and the need for regulatory controls to ensure safety and quality are therefore crucial. This research, therefore, is aimed at examining microbial contamination in unorthodox ophthalmic medications found on the Ghanaian market.

\section{Methods}

\section{Sample collection and preparation}

The unorthodox medicinal products were obtained in their original packages from different herbal and homeopathic clinics and local vendors across the 10 regions of
Ghana using the snowball method. In a situation where multiple branches existed across the regions, only products that were marked were used to avoid duplication. The samples that were in powder and solid form, were reconstituted into homogeneous solutions according to the instructions of the vendor or the manufacturer. This was done to stimulate the form of application. The products were collected in their original packages and sent to the Microbiology Laboratory of the Department of Biomedical Sciences, University of Cape Coast for analysis. The period of sample collection spanned from December 2017 to April 2018.

\section{Preparation of culture media}

Culture media used were Peptone water, Nutrient Agar, Blood Agar, MacConkey Agar, Plate Count Agar and Sabouraud Dextrose Agar (all from Oxoid Limited, Thermo Fisher Scientific Inc., UK). These culture media were prepared as per the manufacturer's instruction leaflet and under standard sterile conditions in order to prevent external contaminations. Other media such as the Tryptone Soy Agar (TSA) (Oxoid Limited, Thermo Fisher Scientific Inc., UK) was used for storing pure isolates for further evaluation in the study. Mannitol Salt Agar (Oxoid Limited, Thermo Fisher Scientific Inc., UK) was used for the identification of Staphyloccocus aureus. Shigella-Salmonella Agar (Oxoid Limited, Thermo Fisher Scientific Inc., UK) were used for the identification of Shigella. Triple sugar iron Agar (HiMedia Laboratories Pvt. Ltd., India) and Citrate Agar (Oxoid Limited, Thermo Fisher Scientific Inc., UK) were also used in the biochemical assay of the various microbes found. Müller Hinton Agar (Oxoid Limited, Thermo Fisher Scientific Inc., UK) was also used in the culture and sensitivity testing. All these were prepared as directed by the manufacturer's leaflet.

\section{Cultivation of sample}

A $1 \mathrm{ml}$ of the liquid sample was added to $9 \mathrm{ml}$ of peptone water (the maximum recovery diluent, MRD) and incubated at $37^{\circ} \mathrm{C}$ for 6 hours. The samples were serially diluted (dilution factor: $\mathrm{x} 10^{6}$ ) to prevent overgrowth during culturing. The samples were plated using the pour plate method; $1000 \mu \mathrm{L}$ of the serially diluted samples were inoculated into clean autoclaved Petri dishes. Some $25 \mathrm{~mL}$ of the culture media (Blood Agar, Sabouraud Dextrose Agar, MacConkey or Plate CAgar) were then poured into the plates, swelled gently and allowed to solidify. The 
solidified plate samples were then incubated (Panasonic cooled incubator MIR-154. Wolf Laboratories Limited, Colenso House, YORK, UK) at $37^{\circ} \mathrm{C}$ for 24 hours for the bacteria and $25^{\circ} \mathrm{C}$ for the fungi respectively. Discrete visible viable colonies seen after 24 hours were counted and documented. This allowed for the computation of the Colony Forming Units (CFUs), of viable bacterial cells expressed as $\mathrm{CFU} / \mathrm{mL}$.

The colonies were classified based on their morphological characteristics, isolated and sub-cultured in TSA. The pure cultures were then stored under $-80^{\circ} \mathrm{C}$ for later identification studies.

\section{Identification of microbes}

The micro-organisms isolates were identified using several benchmarks such as morpho-cultural characteristics, Gram staining, biochemical, selective and differential agars. Appearance (hemolysis pattern) on Blood agar and colony appearance constituted the morpho-cultural properties. Further identification of Gram- negative bacteria was done using the biochemical testing such as Catalase, Indole, Triple Sugar Iron reduction, Eosin Methylene Blue, Urease and Citrate tests. However, Gram- positives were identified using hemolysis pattern on Blood agar, Catalase, Oxidase and Coagulase tests. Lacto-phenol cotton blue was used to identify the growth on the Sabouraud Dextrose Agar. The prepared slides were examined using the $\mathrm{x} 100$ magnification of the light microscope (Olyumpus CX4, Japan) after a drop of oil was placed on the smear. The morphology of the bacteria was then assessed. This together with their growth characteristics on the agar was used to identify the bacteria.

\section{Anti-microbial susceptibility tests}

The anti-bacterial susceptibility testing was performed in-vitro using the disk diffusion method. A standardized suspension of the isolated bacteria was prepared by inoculating a colony into $10 \mathrm{~mL}$ peptone water and incubated at $37{ }^{\circ} \mathrm{C}$ for 24 hours. It was then diluted to 0.5 MacFarland turbidity standards. A labelled sterile swab stick was dipped into the test tube and pressed against the wall of the tube to avoid excess fluid on the media and streaked across the whole surface of the Mueller Hinton Agar plate (Oxoid Basingstoke, UK). The agar was left for 15 minutes for the surface moisture to dry. The antibiotics discs (Abtek Biologicals, Liverpool, UK and Axiom Laboratories, New Delhi, Delhi, India) were then placed on the surface of the inoculated medium. The plate was then incubated at $37 \circ \mathrm{C}$ for 18 hours. The zones of growth inhibition were recorded. The results were compared with the table provided by the Clinical and Laboratories Standards Institute. ${ }^{12}$ After incubation, the zone of inhibition was measured using an interpretative flow chart.

The method used in the fungal sensitivity testing was the well diffusion method which assessed the efficacy of Ketoconazole and Fluconazole at dose levels of 5 to $15 \mathrm{mg} /$ $\mathrm{ml}$. A sterile swab was dipped into the standardized inoculum and used to inoculate evenly the surface of already prepared Sabouraud Dextrose Agar. The wells were created in the plated media and then incubated at $25^{\circ} \mathrm{C}$ for 5 days.

\section{Statistical analysis}

One-way ANOVA followed by Bonferroni posttest was used to compare the mean values of the various treatment groups. Values were expressed as the mean \pm standard error of the mean. A P-value $\leq 0.05$ was considered to be statistically significant. GraphPad Prism (version 5.03; GraphPad, La Jolla, CA, USA) was used in the data analysis.

\section{Ethical consideration}

Ethical clearance was obtained from the Institutional Review Board of the University of Cape Coast. Biosafety guidelines for protection of personnel in the laboratory were observed.

\section{Results \\ Profile of samples collected}

A total of 27 unorthodox ophthalmic preparations were obtained from the various outlets (herbal and homeopathic clinics, and local vendors). Greater Accra had the largest number of samples $(12,44.4 \%)$ with the least (one, 3.7\%) from the Northern Region. Out of the 27 preparations, $16(59.3 \%)$ were packaged in bottles, nine $(33.3 \%)$ in plastic rubber, one $(3.7 \%)$ in a tea bag and another one $(3.7 \%)$ was formulated as a capsule (Figure 1). Of the samples collected, 11 (40.7\%) were anti-allergic preparations, two $(7.5 \%)$ were anti-glaucoma agents, four $(14.8 \%)$ were anti-infectives and some 10 (37.0) were anti-inflammatory agents as per the manufacturer's indication. The routes of administration of these were oral $(16,59.3 \%)$ and topical (Conjunctival) (11, 40.7\%). Only one of the 27 samples had Food and Drug Authority of Ghana's batch number indicating approval. 

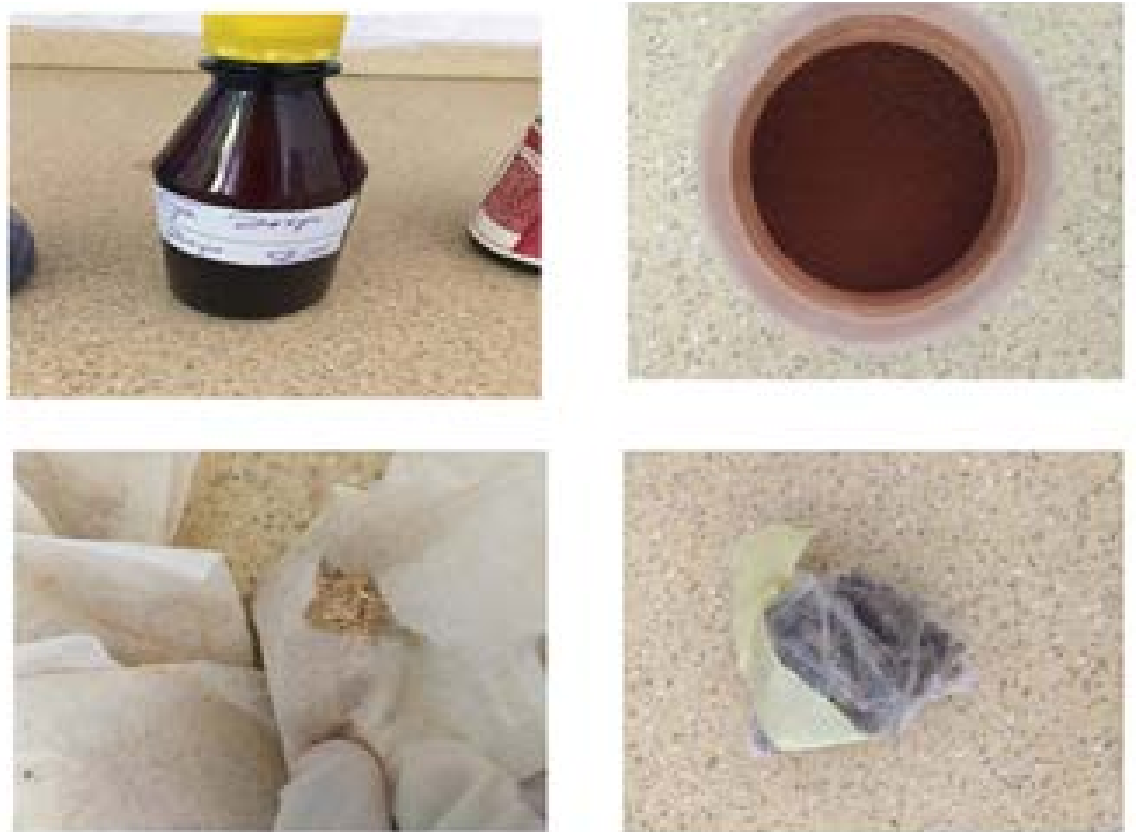

Pictures showing the dosage form, and packaging of some unorthodox ophthalmic preparations sampled.

\section{Identification of cultivated samples.}

There were positive cultures for all 27 samples on Blood, Plate Count, MacConkey Agars, however 11 positive cultures were observed on Sabouraud Dextrose Agars (Figure 2). Gram staining, microscopy indicated the presence of Gram- positive cocci bacteria and Gram- negative bacilli (Figure 2). The colonies on Sabouraud Dextrose Agars stained with Lacto-phenol cotton blue indicating the presences of filamentous and septate fungal hyphae (Figure 2).
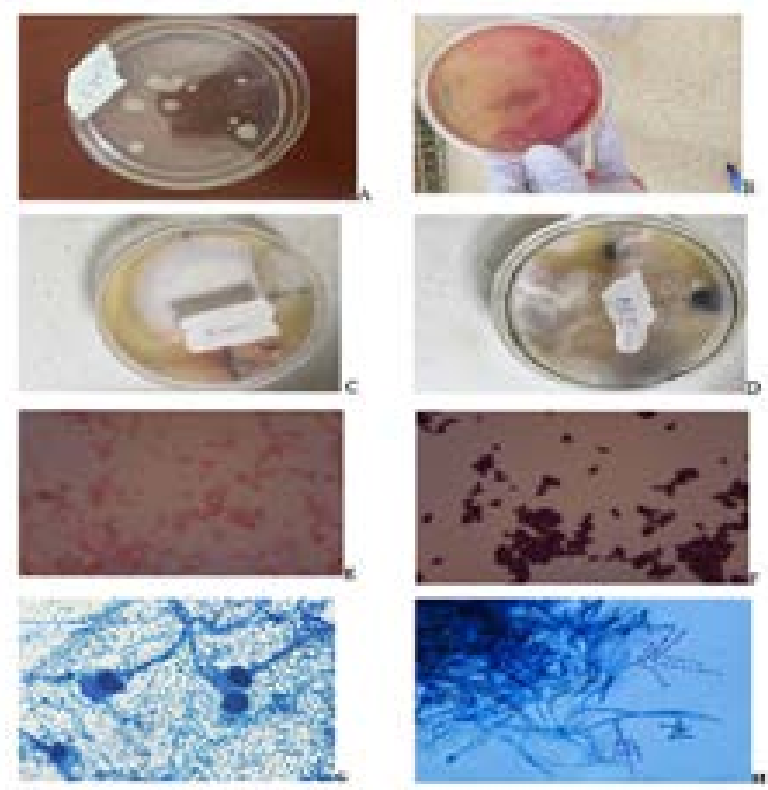

Plates showing (A) a sample cultured on Plate count agar for colony counting and (B) subculture of colony on Blood Agar plate to assess for hemolysis; (C) \& (D) fungal growth; (E) a Gram-negative bacillus (rod) visualised under the oil emersion lens of a LM; (F) a Gram-positive cocci bacteria viewed under the $x 100$ lens (oil emersion); (G) a filamentous fungi (hyphae) and $(\mathrm{H})$ a septate fungal hyphae. Both stained with Lactophenol blue and viewed under the light microscope using the X40 lens. 


\section{Profile of microbial contamination}

Of the isolates, 17 (35.4\%) were Staphylococcus aureus, 15 (31.3\%) were Bacilli spp., five (10.4\%) were Serratia spp., four (8.2\%) were Escherichia coli, three (6.3\%) were Psendomonas spp., two (4.2\%) were Klebsiella spp. and two (4.2\%) were Shigella spp. Staphylococcus aureus was the most occurring bacteria isolated with Klebsiella spp. and Shigella spp. being the least occurring. There were 11 fungal isolates, Penicillium spp. (four, 36.4\%), two were Cephalosporium spp. $(18.2 \%)$, Cercosporium spp. were two $(18.2 \%)$ and Clasdosporium spp. (three, $27.2 \%$ ). Penicillium spp was the most occurring fungal isolate with Cephalosporium spp. and Cercosporium spp. being the least. The bacterial load as indicated by Colony Forming Units confirmed the large Staphylococcus aureus contamination (Table 1 ).

Table 1: The colony forming units of the bacteria isolated.

\begin{tabular}{ll}
\hline Bacteria isolated & CFU $\left(\times \mathbf{1 0}^{5}\right)(\mathbf{\%})$ \\
\hline Staphylococcus aureus & $97(43.11)$ \\
Bacilli spp. & $55(24.44)$ \\
Klebsiella spp & $21(9.33)$ \\
Escherichia coli & $18(8.00)$ \\
Pseudomonas spp. & $17(7.56)$ \\
Serratia spp. & $12(5.33)$ \\
Shigella spp. & $5(2.22)$ \\
\hline TOTAL & $\mathbf{2 2 5 ( \mathbf { 1 0 0 } )}$ \\
\hline
\end{tabular}

\section{Contamination per the dosage forms}

Of the 27 samples collected, $17(35.4 \%)$ bacterial contaminants were found in liquid preparations, 25 (52.1\%) in powdered preparations and six (12.5\%) in solid mass preparations while the fungal contaminants in liquids were four $(36.4 \%)$, five $(45.5 \%)$ in powdered preparations and two $(18.1 \%)$ were found on solid mass preparations.

\section{Contamination per the packaging}

Unorthodox ophthalmic preparations were packaged in bottle (container), plastic rubber or Tea bag. From this study, out of the 27 samples; 26 contaminants were isolated from the 16 samples packaged in bottles, 26. Some 9 samples packaged in plastic rubber had 18 contaminants isolated. A sample packaged in Tea bag had 2 contaminants isolated and another formulated as capsule had 2 contaminants isolated. Only preparations in bottles and plastic rubbers were contaminated with eight and five fungi respectively.

\section{Contamination per the class of the preparation}

The type of ophthalmic preparations found on the Ghanaian market included anti-allergics, anti-glaucomas, anti-infectives, and anti-inflammatories. From this study, 11 samples were anti- allergic preparations with 21 bacterial contaminants. Some 2 samples were anti-glaucomas with 3 contaminants. Four (4) samples were anti-infectives from which 9 contaminants were isolated. Ten 10 samples were in the anti-inflammatory category with 15 contaminants. Of the 11 fungal contaminants, 6 (54.55\%) were in anti-allergic preparations, $3(27.27 \%)$ were found in anti-inflammatories and $1(9.09 \%)$ each in anti-infectives and anti-glaucomas.

\section{Contamination per the class of the route of admin- istration}

Among a total of 16 samples indicated for oral administration, $17(35.4 \%)$ bacterial contaminants were found while the other 11 samples meant to be applied topically (Conjunctival) to the eye, $31(64.6 \%)$ contaminants were isolated. There were $4(36.4 \%)$ fungal contaminants in the preparations intended for oral and 7 (63.6\%) for those intended for topical (Conjunctival) routes of administration.

\section{Antimicrobial susceptibility testing}

The susceptibility tests performed categorized the isolates as resistant, intermediate and susceptible to each of the antibiotics found on the disc. ${ }^{13}$ Table 2 is a summary of these results for antimicrobial susceptibility test of isolated bacteria found. 
Table 2: Showing the zone of inhibition by use of the antibiotic standard disc.

\begin{tabular}{|c|c|c|c|c|c|c|c|c|c|c|c|c|c|c|c|c|}
\hline ORGANISM & GM & OF & $\mathbf{A K}$ & $\mathbf{L E}$ & TE & $\mathbf{A S}$ & $\mathbf{B A}$ & $\mathbf{C F}$ & TZP & $\mathrm{CH}$ & $\mathbf{C P}$ & $\mathbf{C I}$ & $\mathbf{L M}$ & RF & $\mathbf{C X}$ & PR \\
\hline Serratia spp. & $\mathrm{S}$ & $\mathrm{S}$ & $\mathrm{S}$ & $\mathrm{S}$ & $\mathrm{R}$ & $\mathrm{R}$ & $\mathrm{S}$ & $\mathrm{R}$ & $\mathrm{R}$ & $\mathrm{R}$ & $\mathrm{R}$ & $\mathrm{R}$ & $\mathrm{n} / \mathrm{a}$ & $\mathrm{S}$ & $\mathrm{R}$ & $\mathrm{n} / \mathrm{a}$ \\
\hline $\begin{array}{l}\text { Staphylococcus } \\
\text { aureus }\end{array}$ & $\mathrm{S}$ & $\mathrm{S}$ & $\mathrm{S}$ & $\mathrm{S}$ & $\mathrm{R}$ & $\mathrm{R}$ & $\mathrm{R}$ & $\mathrm{R}$ & $\mathrm{n} / \mathrm{a}$ & $\mathrm{R}$ & $\mathrm{S}$ & $\mathrm{R}$ & $\mathrm{S}$ & $\mathrm{S}$ & $\mathrm{R}$ & $\mathrm{S}$ \\
\hline Bacillus spp. & $\mathrm{S}$ & $\mathrm{n} / \mathrm{a}$ & $\mathrm{n} / \mathrm{a}$ & $\mathrm{n} / \mathrm{a}$ & $\mathrm{n}$ & $\mathrm{R}$ & $\mathrm{R}$ & $\mathrm{R}$ & $\mathrm{n} / \mathrm{a}$ & $\mathrm{R}$ & $\mathrm{S}$ & $\mathrm{R}$ & $\mathrm{S}$ & $\mathrm{S}$ & $\mathrm{R}$ & $\mathrm{S}$ \\
\hline $\begin{array}{l}\text { Escherichia } \\
\text { coli }\end{array}$ & $\mathrm{S}$ & $\mathrm{S}$ & $\mathrm{S}$ & $\mathrm{S}$ & $\mathrm{R}$ & $\mathrm{R}$ & $\mathrm{S}$ & $\mathrm{R}$ & $\mathrm{S}$ & $\mathrm{S}$ & $\mathrm{S}$ & $\mathrm{R}$ & $\mathrm{n} / \mathrm{a}$ & $\mathrm{n} / \mathrm{a}$ & $\mathrm{R}$ & $\mathrm{n} / \mathrm{a}$ \\
\hline Klebsiella spp. & $\mathrm{S}$ & $\mathrm{S}$ & $\mathrm{S}$ & $S$ & $\mathrm{~S}$ & $\mathrm{R}$ & $\mathrm{S}$ & $\mathrm{S}$ & $\mathrm{R}$ & $\mathrm{R}$ & $\mathrm{S}$ & $\mathrm{R}$ & $\mathrm{n} / \mathrm{a}$ & $\mathrm{n} / \mathrm{a}$ & $\mathrm{R}$ & $\mathrm{n} / \mathrm{a}$ \\
\hline $\begin{array}{l}\text { Pseudomonas } \\
\text { spp. }\end{array}$ & $\mathrm{S}$ & $\mathrm{R}$ & $\mathrm{S}$ & $\mathrm{S}$ & S & $\mathrm{R}$ & $\mathrm{R}$ & $\mathrm{R}$ & $\mathrm{S}$ & $\mathrm{R}$ & $\mathrm{S}$ & $\mathrm{R}$ & $\mathrm{n} / \mathrm{a}$ & $\mathrm{n} / \mathrm{a}$ & $\mathrm{R}$ & $\mathrm{n} / \mathrm{a}$ \\
\hline Shigella spp. & $\mathrm{S}$ & I & $\mathrm{S}$ & $\mathrm{R}$ & $\mathrm{R}$ & $\mathrm{R}$ & $\mathrm{S}$ & $\mathrm{R}$ & $\mathrm{S}$ & $\mathrm{R}$ & $\mathrm{S}$ & $\mathrm{R}$ & $\mathrm{n} / \mathrm{a}$ & $\mathrm{n} / \mathrm{a}$ & $\mathrm{R}$ & $\mathrm{n} / \mathrm{a}$ \\
\hline
\end{tabular}

Figures $3 \& 4$ are also the summary of the minimum inhibition concentration (MIC) of Ketoconazole and Fluco- nazole on identified fungi species. Ketoconazole and Fluconazole at doses of 5 to $15 \mathrm{mg} / \mathrm{ml}$ did show comparable inhibitory effect for all fungal isolates $(\mathrm{p}>0.05)$.

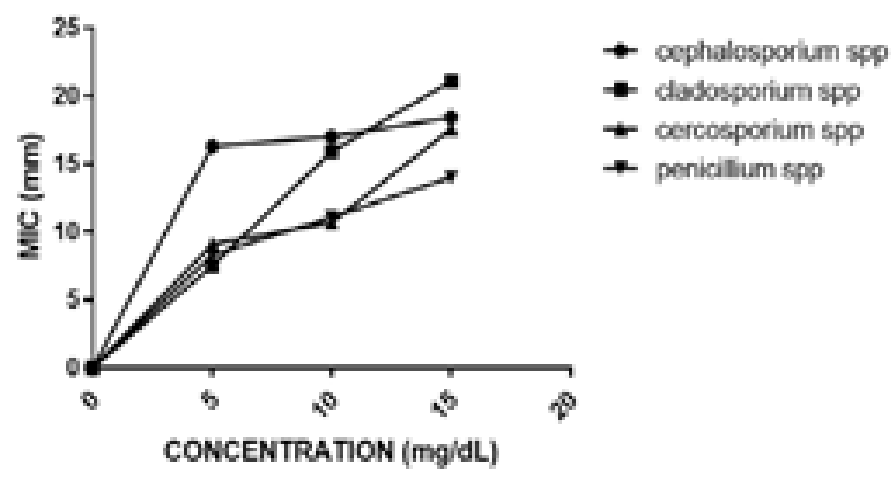

A plot the area under the curve of the concentrations of Ketoconazole against zones of inhibition. Oneway ANOVA indicated that Ketoconazole at all dose levels had a comparable effect on all 4 species isolated.

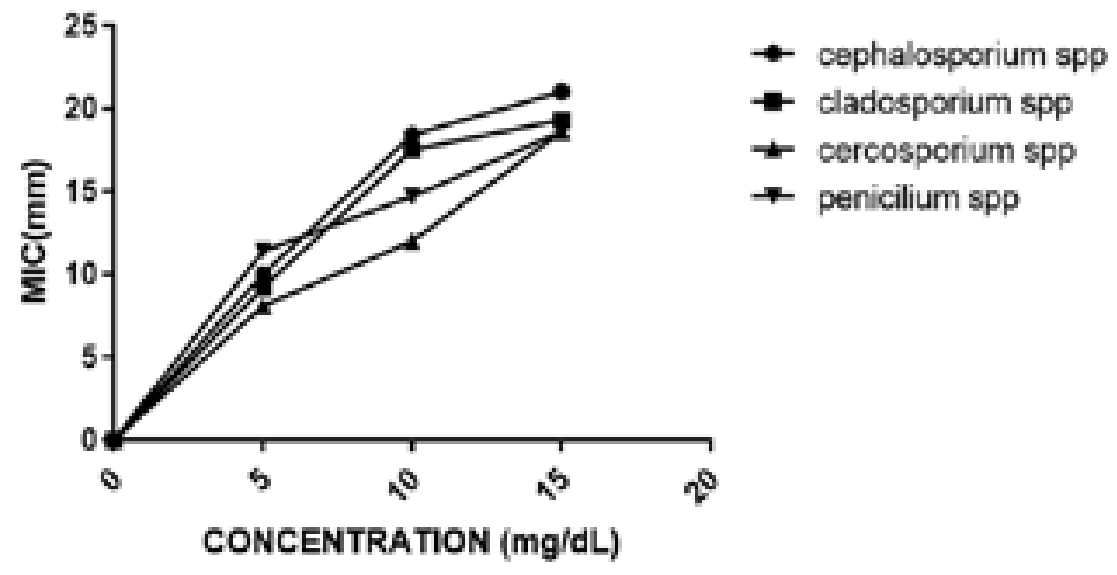

A plot the area under the curve of the concentrations of Fluconazole against zones of inhibition. Oneway ANOVA indicated that Fluconazole at all dose levels had a comparable effect on all 4 species isolated. 


\section{Discussion}

There is a high subscription to unorthodox medications in Africa for which several reasons have been cited. Notable among these is the fact that this practice is embedded in the cultural patrimony of most Africans, religious beliefs, past experiences, traditional beliefs and behaviours, the influence of friends and relatives and economic consideration. ${ }^{14}$ A large number of the preparations without FDA batch number could be due to challenges in control and regulation. It has been acknowledged by the FDA of Ghana that there has been an upsurge in the number of herbal clinics most of which are into preparations meant for use within their facilities. However, these products find their way into the market. This coupled with the influx of unapproved preparations through unapproved routes owing to the porosity of the borders of Ghana remains a challenge in the control and regulation of these agents. ${ }^{15}$

Infectious diseases including eye infections and diarrheal diseases remain an important part of the disease burden in Ghana. There is a huge amount of the health care budget allocated to fighting these diseases at the expense of non-communicable diseases despite the double burden of disease that confronts the nation. ${ }^{16,17}$ Control and regulatory measures are therefore essential to prevent the conduits through which these infections are contracted. The microbial quality of unorthodox preparations has been a matter of concern given the renaissance of this practice as a key means of primary health care to many living in both rural and urban regions of Ghana. Contrary to the long-held beliefs that the use of unorthodox medicines is only popular among the rural poor, the majority of these preparations were retrieved from the major cities of Ghana, with Accra harbouring the most of these clinics and vendors.

The main classes of unorthodox medication meant for ophthalmic use were anti-infectives, anti-glaucomas, anti-allergics and anti-inflammatories. This indicates the major ocular disorders for which the populace seek for remedy. This stems from the fact that ocular allergies, glaucomas and infections constitute a major ocular disease burden in Ghana. The poor environmental and sanitary conditions in most developing countries tend to support the proliferation of infectious pathogens. ${ }^{18}$

All samples collected were grossly contaminated beyond the acceptable microbial value. ${ }^{19,20}$ The heavy microbial loads of pathogenic tendencies isolated from the samples had serious consequences for its users irrespective of the route of administration indicated. The two major routes indicated were oral and topical (conjunctival) routes. The isolates included E. coli, Shigella spp., Serratia spp and Pseudomonas spp. E. coli and Shigella spp. for example, are associated with the gastrointestinal tract and indicate the possibility of fecal contamination. ${ }^{21}$ These contaminants might have been introduced through the poor quality of water used in the preparation process. Apart from poor water quality as the potential source of enteric pathogenic contaminants, the use of plant parts that had prior contact with manure could also result in similar contamination. In addition, some plant materials have been found to be reservoirs of some enteric pathogens. ${ }^{23}$ The presence of Escherichia coli and Shigella spp. are suggestive of poor quality of production and havesting practices associated with most unorthodox preparations. ${ }^{19}$ Contrary to previous reports that associated Serratia spp with nosocomial infections, recent studies have reported its involvement in diarrhoeas which has no link with HIV infection and eye infections. ${ }^{24,25}$ It has been found to destroy microvilli and formation of vacuoles ${ }^{24}$. Their natural habitat of water and the soil makes them an important probable contaminant of these unorthodox medicines. ${ }^{25}$ Pseudomonas spp., on the other hand, have been reported as capable of penetrating intact cornea epithelium posing a risk of corneal damage. ${ }^{22}$ Bacillus species are known to be the most common naturally occurring aerobic spore-forming bacteria microflora of medicinal plants indicative of soil contamination. The occurrence of $S$. aureus suggests contamination from human activities possibly through the handling of raw materials and the manufacturing process. Klebsiella causes a range of human diseases, which is dependent on where it is found in the body. However, Klebsiella normally inhabits human intestines as harmless pathogens from where it spreads to other tissues. There has been a reported association between $K$. pneumoniae endophthalmitis and concurrent hepatic abscess ${ }^{26-28}$ in that more than $50 \%$ of patients with $K$. pneumoniae endophthalmitis suffer concomitant hepatic abscess. The fungal contaminants found further buttress the possibility of exposure of the raw materials to the soil. Penicillium spp, Cercosporium spp, Cephalosporium spp and Clasdoporium spp are found in the soil, decaying vegetations and are common contaminants on various substances raw materials for herbal products if proper harvesting or sanitation practices are not adhered to. Penicillium spp is a frequent cause of conjunctival infection. ${ }^{27}$ Cephalosporium spp spreads through the soil and 
contaminates the roots of plants. Cephalosporium spp can cause scleral infections and a decreased corneal sensation. ${ }^{28}$ Clasdosporium spp. on the other hand, causes Clasdosporium Keratitis $^{29}$ while Cercosporium spp is also a known cause of ocular infections. Another potential means that could be contributing to the contaminations observed is poor storage practices. Most manufacturers and vendors do not adhere to strict guidelines pertaining to temperature control for the liquid dosage form as well as for the powdered preparations. ${ }^{30}$

The absence of a label which characterized all of the herbal preparations without FDA batch number posed a significant challenge of product specifications and identification in terms of concentration and composition of each of the preparations. An ideal packaging should be such that it does not adversely affect the microbial quality of intended preparations. The unorthodox preparations were packaged mainly in bottles and plastic rubbers. These means of packaging were not air-tight, thus contamination by atmospheric microbes was unavoidable. Unlike the fungal isolates which were found to be susceptible to both Ketoconazole and Fluconazole, the bacterial isolates were found to be resistant against the conventional antibiotics except for Gentamicin and Ciprofloxacin. This narrows the spectrum of antibiotic therapy for infections contracted through the use of these agents.

The identity of the contaminants discovered in this study suggested possible sources of the contaminations such as environmental, raw materials, hands of the producers and poor water quality. ${ }^{31}$ This is a clear indication of a high level of non-adherence to the requirements of good manufacturing practices. In conclusion, this study has shown that unorthodox ophthalmic preparations on the Ghanaian market are contaminated with resistant strains of bacteria of ocular and enteric pathogenic propensities. It is therefore recommended that manufacturers and local vendors of these agents be educated on proper hygienic practices pertaining to production. There is an urgent need for FDA of Ghana to strengthen monitoring and quality control measures for unorthodox medicines.

\section{Acknowledgments}

The authors are grateful to Esther Duncan for her support in typesetting this manuscript.

Funding: This research did not receive any specific grant from funding agencies in the public, commercial, or notfor-profit sectors.

\section{Author's conflict of interest:}

The authors declare no known conflict of interest.

\section{References}

1. Mukherjee PW. Quality Control of Herbal Drugs: An Approach to Evaluation of Botanicals. [Reprint]. New Delhi, India: Business Horizons Publishers. 2002.

2. Bodeker G, Ong CK, Grundy CK, Burford G, Shein K. WHO Global Atlas of Traditional, Complementary and Alternative Medicine. Geneva, Switzerland: World Health Organization Centre for Health Development 2005.

3. Bandaranayake W M. Quality control, screening, toxicity, and regulation of herbal drugs: In: Ahmad I, Aqil F, Owais M editorsModern Phytomedicine:Turning Medicinal Plants into Drugs. Weinheim:Wiley-VCH GmbH \& Co. KGaA. 2006. p 25-57.

4. Commodore SGO. Welcome address. Proceedings of the Ist Traditional medicine and modern health care: partnership for the future: national consensus-building symposium on the policies on traditional medicine in Accra, Ghana 1995.Aziato L, Antwi HO. Facilitators and barriers of herbal medicine use in Accra, Ghana: an inductive exploratory study. BMC Comp Alt Med 2016;16:142.

5. Adeleye IA, Okogi G, Ojo EO. Microbial contamination of herbal preparations in Lagos, Nigeria. $J$ Health Popul Nutr 2005; 23:296-7.

6. Kneifel W, Czech E, Kopp, B. Microbial contamination of medicinal plants- A review. Planta Med 2002; 68: 5-15.

7. Sandle T. The test for sterility of medicinal products. IJOMAS 2014; 1: 1-9.

8. Upadhyay MP, Srinivasan M, Whitcher JP. Microbial keratitis in the developing world: does prevention work? Int Ophthalmol Clin 2007 Jul;47: 17-25.

9. McCormick BJJ, Lang DR. Diarrheal disease and enteric infections in LMIC communities: how big is the problem? Review. Trop Dis Travel Med Vaccines 2016; 2:11. 10. Mugoyela V, Mwambete KD. Microbial contamination of nonsterile pharmaceuticals in public hospital settings. Ther Clin Risk Manag 2010; 6: 443-448.

11. Perilla MJ, Ajello G, Bopp C. et al. Manual for the laboratory identification and antimicrobial susceptibility 
testing of bacterial pathogens of public health importance in the developing world: Haemophilus influenzae, Neisseria meningitidis, Streptococcus pneumoniae, Neisseria gonorrhoea, Salmonella serotype Typhi, Shigella, and Vibrio cholerae. Centers for Disease Control and Prevention and World Health Organization, Department of Communicable Disease Surveillance and Response, Atlanta, Ga, USA 2003; 6:1-369.

12. Sharma S. Ocular Microbiology. 1st Ed. Madurai: Aravind Eye Hospital Publication, 1998.

13. Erah PO. Herbal medicines: challenges. Trop J Pharm Res 2002; 1:53-54.

14. Amartey A. Challenges in regulating herbal medicines in Ghana. Proceedings of the 14th International Conference of Drug Regulatory Authorities, ICDRA; 2010 Nov. 30 - Dec. 3 -Singapore;2010.

15. Adams I, Darko D, Accorsi S. The burden of diseases: brief overview of disease profile, service utilisation patterns and health outcomes. Bull Health Info 2004 Oct; 1:.7-11.

16. Kushitor MK, Boatemaa S. The double burden of disease and the challenge of health access: Evidence from Access, Bottlenecks, Cost and Equity facility survey in Ghana. PLoS One 2018; 13: e0194677.

17. Krämer A, Kretzschmar M, Krickeberg K. Modern Infectious Disease Epidemiology: Statistics for Biology and Health, $1^{\text {st }}$ ed. Springer-Verlag New York; 2010.

18. World Health Organization. Department of Technical Cooperation for Essential Drugs and Traditional Medicine.: Guidelines for assessing quality of herbal medicines with reference to contaminants and residues. Geneva: World Health Organization; 2007. 105p.

19. European Pharmacopoeia. Microbiological quality of pharmaceutical preparations. $6^{\text {th }}$ Ed. Strasbourg: 2007 Jan. 50104 P 4451-4452.

20. Edberg SC, Rice EW, Karlin RJ. et al. Escherichia coli: the best biological drinking water indicator for public health protection. Symp Ser Soc Appl Microbiol 2000;88:106S-116S.
21. Alarcon I, Tam C, Mun JJ. et al. Factors impacting corneal epithelial barrier function against Pseudomonas aeruginosa traversal. Invest Ophthalmol V is Sci 2011; 52: 1368-1377.

22. Holden MTG, Heather Z, Paillot R. et al. Genomic evidence for the evolution of Streptococcus equi: Host restriction, increased virulence, and Genetic Exchange with Human Pathogens. PLoS Pathog 2009; 5:1-14.

23. Ochieng JB, Boisen N, Lindsay B. et al. Serratia marcescens is injurious to intestinal epithelial cells. Gut Microbes 2014; 5:729-36.

24. Buckle J. Infection in: Clinical Aromatherapy: Essential Oils in Healthcare. $3^{\text {rd }}$ Ed. Churchill Livingstone, 2015.

25. Ko W, Paterson DL, Sagnimeni AJ. et al.. Community- acquired Klebsiella pneumoniae bacteremia: global differences in clinical patterns. Emerg Infect Dis 2002; 8:160-166.

26. Chou FF, Kou HK. Endogenous endophthalmitis associated with pyogenic hepatic abscess. J Amer Coll Surg 1996; 182:33-36.

27. Chee SP, Ang CL. Endogenous Klebsiella endophthalmitis - a case series. Ann Acad Med Sing 1995; 24:473-478.

28. Miguélez S, Obrador P, Vila J. Conjunctival infection due to penicillium SP. Arch Soc Esp Oftalmol 2003; 78:55-7.

29. Reddy JC, Murthy SI, Reddy AK. et al. Risk factors and clinical outcomes of bacterial and fungal scleritis at a tertiary eye care hospital. Middle East Afr J Ophthalmol 2015; 22: 203-211.

30. Cheng SC-H, Lin Y-Y, Kuo CN et al. Cladosporium keratitis:a case report and literature review. BMC Ophthalmol 2015; 15:106.

31. World Health Organization. WHO guidelines on Good Manufacturing Practices (GMP) for herbal medicines. WHO Press 20 Avenue Appia, 1211 Geneva 27 Switzerland: World Health Organization .2007.72p. 